\title{
Effect of Hindlimb Unweighting on Expression of Hypoxia-Inducible Factor-1 $\alpha$, Vascular Endothelial Growth Factor, Angiopoietin, and Their Receptors in Mouse Skeletal Muscle
}

\author{
A. WAGATSUMA \\ Department of Biochemical Sciences, National Institute of Fitness and Sports, Shiromizu, Kanoya, \\ Kagoshima, Japan
}

Received May 19, 2007

Accepted June 28, 2007

On-line July 26, 2007

\begin{abstract}
Summary
Hindlimb unweighting (HU) leads to capillary regression in skeletal muscle. However, the molecular mechanism(s) remains to be elucidated. To gain insight into the regulation of this process, we investigated gene expression of hypoxia-inducible factor-1 $\alpha$ (HIF-1 $\alpha$ ), vascular endothelial growth factor (VEGF), angiopoietin, and their receptors in the atrophied muscle induced by $\mathrm{HU}$. The hindlimbs of mice were unweighted by tailsuspension and then the gastrocnemius muscles were isolated after 10 days. To assess the capillary distribution, the capillary endothelium in frozen transverse sections was identified by staining for alkaline phosphatase. The mRNA levels were analyzed using a real-time reverse transcription-polymerase chain reaction. After 10 days of $\mathrm{HU}$, the number of capillaries around a muscle fiber was significantly decreased by $19.5 \%$, suggesting that capillary regression appears to occur. The expression of HIF$1 \alpha$ was significantly down-regulated after 10 days of $\mathrm{HU}$. The expression of VEGF remained unchanged, whereas those of Flt-1, $\mathrm{KDR} / \mathrm{Flk}-1$, and neuropilin-1 were significantly down-regulated, suggesting that VEGF signaling through these receptors would be attenuated. The expression of angiopoietin-1, and -2 , as well as their receptor, Tie-2 were also significantly down-regulated, suggesting that angiopoietin-1 signaling through Tie-2 would be attenuated. These findings suggest that alterations in expression of VEGF, angiopoietins, and their receptors may be associated with capillary regression after $\mathrm{HU}$.
\end{abstract}

\section{Key words}

Angiogenic factor • Capillary regression • Hindlimb unweighting • Muscle atrophy

\section{Corresponding author}

A. Wagatsuma, Department of Information Physics and Computing, Graduate School of Information Science and Technology, University of Tokyo, 3-7-1, Hongo, Bunkyo, Tokyo 113-8656, Japan. Fax: $+81 \quad 3 \quad 58 \quad 41 \quad 68$ 62. E-mail: wagatsuma1969@yahoo.co.jp

\section{Introduction}

The microcirculation system is important for supplying oxygen and substrates to cells as well as for removing metabolites produced by cells. Thus it is essential for the cell to maintain a suitable capillary network under physiological conditions. Skeletal muscle adapts its capillary network to alterations in neuromuscular activity including motor activity and load bearing. A rodent model of hindlimb unweighting (HU), is frequently used to simulate and study neuromuscular perturbations occurring in a real microgravity environment during spaceflights (Morey-Holton and Globus 2002). This earth-based model of microgravity is characterized by reduction of motor activity and lack of load bearing (Talmadge 2000). This model is known to affect capillary distribution of antigravity muscle (Desplanches et al. 1987, 1990, 1991, Kano et al. 2000, Dapp et al. 2004). For instance, capillary-to-fiber ratio, typically used as a measure of capillary distribution, decreases especially in soleus muscle, suggesting that a reduction in the absolute number of capillaries occurs in antigravity muscle. Although the adaptation of muscular vasculature to microgravity is thought to be physiological response to react to an environmental change, the mechanism(s) are still only partially understood. A possible mechanism has been proposed that apoptotic signaling may play an important role in remodeling of capillary network during HU (Fujino et al. 2005). HU spontaneously induces apoptosis of vascular endothelial cell in soleus muscle. The apoptotic process should be mediated, at least in part, by specific angiogenic factors 
such as vascular endothelial growth factor (VEGF) and angiopoietin. Recently, we investigated the expression of angiogenic factors to gain insight into the regulation of muscle denervation-induced capillary regression (Wagatsuma et al. 2005, Wagatsuma and Osawa 2006). The expression of angiogenic factors was down-regulated in short- and long-term muscle denervation. Muscle denervation is different from $\mathrm{HU}$ in that neuromuscular activity is completely inhibited (Talmadge 2000). Therefore, the molecular response to HU may be different from that of muscle denervation. To our knowledge, it remains to be elucidated the expression patterns of angiogenic factors after HU.

Hypoxia-inducible factor 1 (HIF-1) is a heterodimeric transcriptional factor consisting of HIF-1 $\alpha$ and HIF-1 $\beta$ subunits (Semenza 1999). HIF-1 acts as a master regulator of numerous hypoxia-inducible genes including VEGF (Levy et al. 1995) and Flt-1 (Gerber et al. 1997) which are related to angiogenesis. The biological activity of HIF-1 is determined by the expression and activity of the HIF-1 $\alpha$ subunit (Jiang et al. 1997). Targeted inactivation of HIF-1 $\alpha$ in the mice results in abnormal vascular development and embryonic lethality (Iyer et al. 1998). In HIFl $\alpha^{-1-}$ mice, defects in angiogenesis have been observed in the developing embryonic tissue, suggesting that HIF- $1 \alpha$ plays a crucial role in angiogenesis. Under normoxia, HIF- $1 \alpha$ protein is rapidly degraded by the ubiquitin-proteasome pathway by binding of the von Hipple-Lindau tumor suppressor protein (Salceda and Caro 1997, Maxwell et al. 1999). However, a previous study has shown expression of HIF$1 \alpha$ protein even in control muscle (Stroka et al. 2001), suggesting that HIF-1 $\alpha$ protein may be normoxically stabilized in skeletal muscle. Therefore, HIF-1 $\alpha$ may be involved in expression of VEGF and Flt-1 in response to HU.

VEGF, the most potent endothelium-specific mitogen, plays a crucial role in vasculogenesis and angiogenesis (Ferrara 1999). VEGF exerts its biological effects through two tyrosine kinase receptors, fms-like tyrosine kinase (Flt-1) and a kinase insert domaincontaining receptor/fetal liver kinase-1 (KDR/Flk-1), expressed predominantly on endothelial cells (Ferrara 2001). These two receptors exhibit markedly different signaling and biological properties (Ferrara 2001). $\mathrm{KDR} / \mathrm{Flk}-1$ is considered to be the major mediator of several physiological and pathological effects of VEGF on endothelial cells (Cross et al. 2003). KDR/Flk-1 has been implicated in VEGF survival signals in endothelial cells through the phosphatidylinositol 3'-kinase PI3kinase/Akt-dependent pathway (Gerber et al. 1998). This pathway is thought to be important in protection from apoptosis (Yao and Cooper 1995). Neuropilin-1 is also a VEGF receptor that modulates VEGF binding to KDR and may regulate VEGF-induced angiogenesis (Soker et al. 1998). Therefore, VEGF signaling, at least in part, mediated by KDR/Flk-1/neuropilin-1 may be attenuated, resulting in capillary regression induced by $\mathrm{HU}$.

Angiopoietins are also angiogenic factors that make essential contributions to the maturation, stabilization, and remodeling of the vasculature (Fam et al. 2003). The biological effects of angiopoietin are mediated by another tyrosine kinase receptor, the tyrosine kinase with Ig and EGF homology domain-2 (Tie-2), which, like the VEGF receptors, is expressed primarily on endothelial cells (Schnurch and Risau 1993). The angiopoietins act in concert with VEGF (Asahara et al. 1998) and are critically important for angiogenesis. Angiopoietin-1/Tie-2 signaling modulates vessel maturation and maintains vessel integrity through the recruitment of pericyte-endothelial cell, whereas angiopoietin-2 blocks angiopoietin-1/Tie-2 signaling, loosening vascular structure, leading vessel regression and apoptosis in the absence of VEGF (Fam et al. 2003). Therefore, the hypothesis of the current study is that 1) alterations in expression of HIF- $1 \alpha$ may be associated with those of VEGF and Flt-1, and 2) VEGF/KDR/Flk1/neuropilin- 1 and angiopoietin- $1 /$ Tie-2 signaling may be attenuated, contributing to capillary regression induced by HU.

To test these hypotheses, we investigated alterations in the expression of these angiogenic factors and their receptors in mouse gastrocnemius muscle after HU. We demonstrated these angiogenic factors would be down-regulated concomitantly with capillary regression after HU.

\section{Materials and Methods}

\section{Animal care and experimental procedure}

Female 7-week-old CD1 mice (Clea Japan, Meguro, Tokyo) were used and were housed in the animal care facility under a 12-h light/12-h dark cycle at room temperature $\left(23 \pm 2{ }^{\circ} \mathrm{C}\right)$ and $55 \pm 5 \%$ humidity. The mice were randomly assigned to one of two groups as follows: $\mathrm{HU}(\mathrm{n}=12)$ or ambulatory control $(\mathrm{n}=12)$. For $\mathrm{HU}$, we have modified a rat hindlimb suspension model originally described (Morey-Holton and Wronski 1981) 
to accommodate it for the use in mice (McCarthy et al. 1997). Briefly, each mouse was weighed and anesthetized with an intraperitoneal injection of pentobarbital (50 $\mathrm{mg} / \mathrm{kg}$ body weight). The bandages (Nichiban, Bunkyo, Tokyo) were wrapped around the tail in a helical pattern starting at the base of the tail. After the mouse had recovered from the anesthetic, a swivel hook was placed through the bandage just distal to the tip of the tail. All procedures in the animal experiments were performed in accordance with the guidelines presented in the Guiding Principles for the Care and Use of Animals in the Field of Physiological Sciences, published by the Physiological Society of Japan. This study was also approved by the Animal Committee of the National Institute of Fitness and Sports, Japan.

\section{Histochemistry}

Gastrocnemius muscle was dissected and frozen in liquid nitrogen-cooled isopentane. Staining of capillaries was performed as described previously (Ziada et al. 1984). Frozen transverse sections from the midbelly region of gastrocnemius muscles were fixed for $10 \mathrm{~min}$ in acetone at $-20^{\circ} \mathrm{C}$ and air-dried before being stained for alkaline phosphatase, which is present in the capillary endothelium. Morphometric measurements of fiber crosssectional area (FCSA) and of capillary distribution were performed using light microscopy with CCD camera in randomly selected fields (average of 10 fields/section) of the superficial region of gastrocnemius muscle. The FCSA was measured using ImageJ $1.36 \mathrm{~b}$ image analysis software (http://www.rsb.info.nih.gov/ij/). To assess the capillary distribution, the number of capillaries around a muscle fiber was directly counted (Wagatsuma 2006).

\section{RNA extraction and $c D N A$ synthesis}

The total RNA preparation was performed on the different muscle piece used for the morphological analysis. Superficial regions of the gastrocnemius muscles predominantly composed of fast muscle fibers were carefully isolated. The tissue was then transferred to glass homogenizers on ice, and $1 \mathrm{ml}$ TRI reagent (Molecular Research Center, Cincinnati, $\mathrm{OH}$ ) was added per $50 \mathrm{mg}$ of tissue. RNA integrity was confirmed by denaturing agarose gel electrophoresis, and the concentration was quantified by measuring the optical density (OD) at $260 \mathrm{~nm}$. All samples had an optical density ratio $\left(\mathrm{OD}_{260} / \mathrm{OD}_{280}\right)$ of at least 1.9 . The DNasetreated total RNA $(1 \mu \mathrm{g})$ was then converted to cDNA using a First-strand cDNA synthesis system for quantitative RT-PCR (Marligen Biosciences, Ijamsville, MD). The cDNA samples were aliquoted and stored at $-80{ }^{\circ} \mathrm{C}$.

\section{Real-time polymerase chain reaction (PCR) analysis}

Real-time PCR was performed using an Opticon $^{\text {TM }}$ DNA Engine (MJ Research, Waltham, MA) according to the manufacturer's instructions. Amplification was carried out using SYBR Premix Ex Taq $^{\text {TM }}$ (Takara Bio, Otsu, Shiga). All primers used in this study were obtained from Espec Oligo Service (Ibaraki, Tsukuba, Japan). The reactions employed primers for HIF-1 $\alpha$ (Simpson et al. 2000), VEGF, Flt-1, KDR/Flk-1, angiopoietin-1, -2, Tie-2 (Shih et al. 2002), neuropilin-1 (Thijssen et al. 2004), and cyclophilin (Shih et al. 2002). For each set of primers, PCR thermal cycle conditions were optimized to achieve a single ethidium bromidestained band following electrophoresis on a $2 \%$ agarose gel. Differences in gene expression were calculated relative to the expression of cyclophilin by comparison with a standard curve. To search the appropriate house keeping gene, we investigated several house keeping genes including $18 \mathrm{~S}$ ribosomal RNA, glyceraldehyde-3phosphate dehydrogenase, $\beta$-actin, and cyclophilin. We selected cyclophilin as house keeping gene because the expression levels remain unchanged in hindlimb unloading muscle relative to control muscle. Cyclophilin was found to be appropriate for normalizing the signal by comparing the differences in raw threshold cycle values (the number of amplification cycles at which the signal is detected above the background and is in the exponential phase). A standard curve was constructed from serially diluted cDNA from gastrocnemius muscle. Each sample was normalized by its cyclophilin content. The final results were expressed as a relative fold change compared to control animals.

\section{Statistical analysis}

Values are means \pm S.E.M. For analysis between control and hindlimb unweighting, Student's $t$-test was used to determine significance. The level of significance was set at $P<0.05$.

\section{Results}

After 10 days of HU, FCSA significantly decreased by $63.5 \%$ (Control: $2789.1 \pm 56.5 \mu \mathrm{m}^{2}$; HU: $1017.9 \pm 17.3 \mu \mathrm{m}^{2}$ ). Figure 1 shows the effect of HU on capillary distribution of skeletal muscle. Muscle fibers 


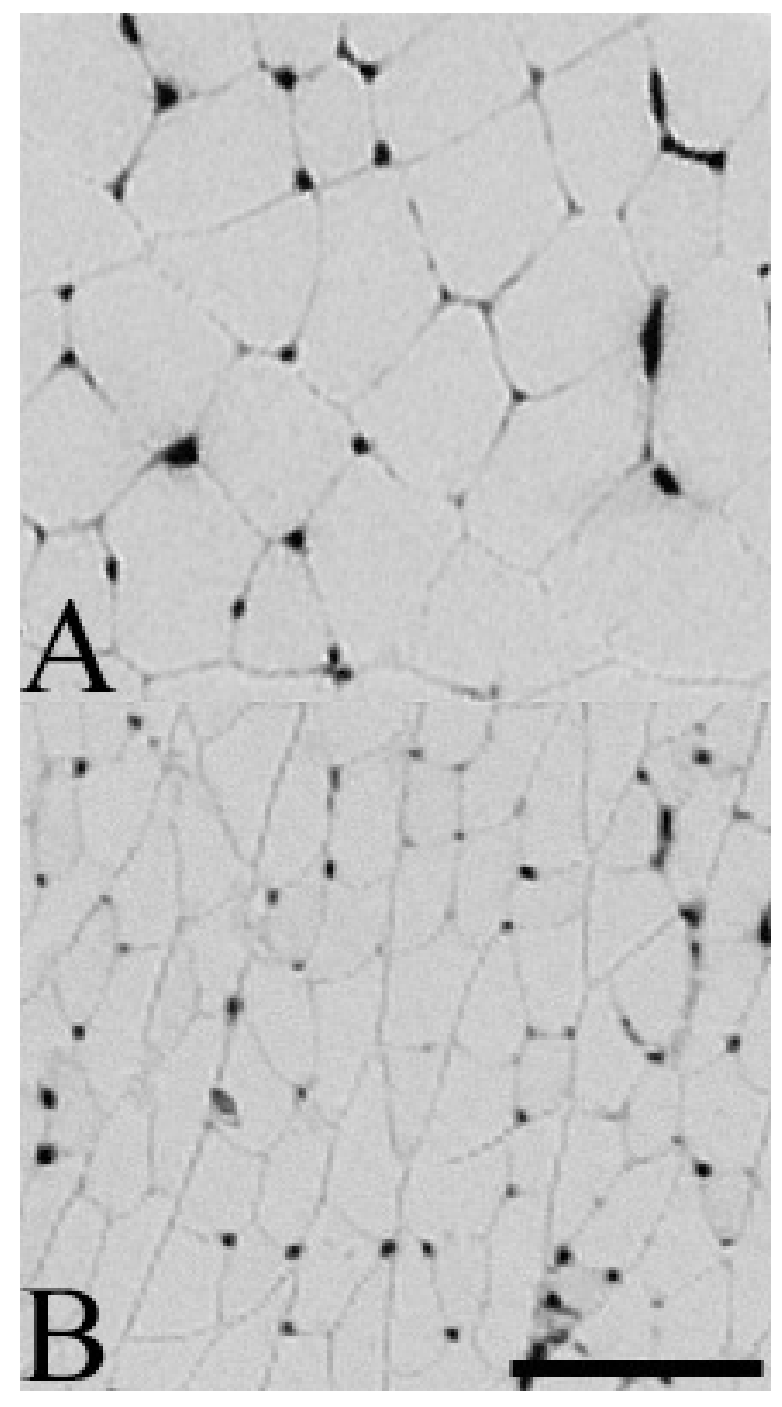

Fig. 1. Identification of capillaries by staining for alkaline phosphatase in control (A), and HU (B). Capillaries appear as black dots. Bar $=100 \mu \mathrm{m}$.

from hindlimb unweighted animals were pathologically atrophied compared to those from control animals. The number of capillaries around a muscle fiber significantly decreased by $19.5 \%$ (Control: 2.72 \pm 0.05 ; HU: $2.19 \pm 0.03$ ) after 10 days of HU. The expression HIF-1 $\alpha$ mRNA transcript significantly decreased by $30 \%$ relative to control muscle (Fig. 2) after 10 days of HU. The expression of VEGF mRNA transcript remained unchanged, whereas those of Flt-1, KDR/Flk-1, and neuropilin-1 mRNA transcripts significantly decreased by $44 \%, 68 \%$, and $71 \%$, respectively, relative to control muscle (Fig. 2). The expression of angiopoietin-1, -2 , and their receptor, Tie- 2 mRNA transcripts significantly decreased by $64 \%, 40 \%$, and $76 \%$, respectively, relative to control muscle (Fig. 3). Furthermore, we calculated the ratio of angiopoietin-2-to-angiopoietin-1 after 10 daysHU. The angiopoietin-2-to-angiopoietin-1 ratio increased

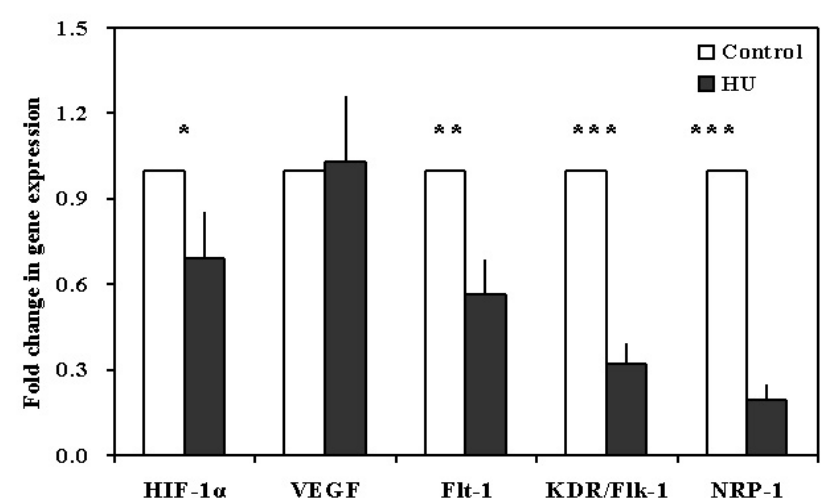

Fig. 2. Effect of $\mathrm{HU}$ on expression of HIF-1a, VEGF, FIt-1, KDR/Flk-1, and neuropilin-1 (NRP-1) mRNA transcripts in skeletal muscle. The values are means \pm S.E. $(n=6) .{ }^{*} p<0.05, * * p<0.01$, $* * * p<0.001$ compared to control muscle.

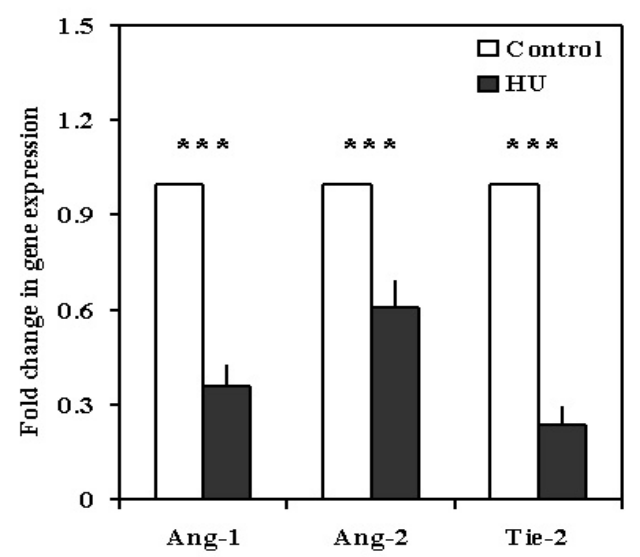

Fig. 3. Effect of $\mathrm{HU}$ on expression of angiopoietin-1 (Ang-1), angiopoietin-2 (Ang-2), and Tie-2 mRNA transcripts in skeletal muscle. The values are means \pm S.E. $(n=6)$. $* * * p<0.001$ compared to control muscle.

by 2.3 -fold in hindlimb unweighted animals compared with control animals.

\section{Discussion}

This study was designed to gain insight into the possible mechanism(s) of capillary regression induced by HU. The main findings of this study were that 1) the number of capillaries around a muscle fiber was decreased after 10 days, 2) the expression of VEGF receptors, Flt-1, KDR/Flk-1, and neuropilin-1 were down-regulated in the atrophied muscle induced by HU, and 3 ) the expression of angiopoietin-1, -2, and angiopoietin receptor, Tie-2 were also down-regulated in the atrophied muscle. These shifts in gene expression would be related to regression of capillaries after $\mathrm{HU}$.

We observed capillary regression after HU. 
Capillary endothelial cells are uniquely exposed to the hemodynamic force such as shear stress of blood flow in vivo. HU does not change blood flow in gastrocnemius muscle (McDonald et al. 1992, Woodman et al. 2001) but decreases erythrocyte concentration in the blood (Overton et al. 1989), suggesting that shear stress loaded on endothelial cells may change, resulting in affecting survival of endothelial cells. Indeed, this possibility may be supported by the observations that shear stress suppresses apoptosis in endothelial cells by PI3kinase/Akt-dependent pathway (Haga et al. 2003).

In the current study, we observed that expression of HIF- $1 \alpha$ gene paralleled that of Flt- 1 gene which is mediated, at least in part, by the binding of hypoxia inducible factor 1 (HIF-1) to an HIF binding site located in the promoters of Flt-1 gene (Gerber et al. 1997), suggesting that HIF-1 $\alpha$ may play a role in regulation of Flt-1 gene expression in response to HU. However, we observed no significant changes in the expression of VEGF, although VEGF is also known as HIF-1 target gene (Levy et al. 1995). However, our data does not rule out the possible involvement of HIF-1 $\alpha$ in activation of the VEGF gene in skeletal muscle, because the regulation of HIF-1 $\alpha$ expression and activity in vivo occurs at multiple levels, including mRNA expression, protein expression, nuclear localization, and transactivation (Semenza 2000). Further studies are needed to elucidate the physiological role of HIF- $1 \alpha$ in the expression of VEGF and Flt-1 genes in response to HU.

The expression of VEGF has been downregulated after short- and long-term muscle denervation (Magnusson et al. 2005, Wagatsuma et al. 2005, Wagatsuma and Osawa 2006). We reported that the expression of VEGF was down-regulated immediately after muscle denervation and then remained to be lower than control levels until 30 days (Wagatsuma and Osawa 2006). Bey et al. (2003) reported quantitative RT-PCR data on the changes in gene expression in skeletal muscle during short-term HU. They observed that the expression of VEGF is immediately down-regulated $12 \mathrm{~h}$ after HU. In the current study, in contrast, we observed no significant changes in VEGF expression levels. We attribute this discrepancy in data to time course of alterations in electromyographic (EMG) activity during HU. The EMG activity of lateral gastrocnemius decreases by half immediately after $\mathrm{HU}$, maintains lower than control levels for 4-5 days, and subsequently tends to recover until 7 days (Alford et al. 1987), suggesting that recovery of EMG activity may contribute to VEGF expression observed in the current study. Indeed, VEGF expression may be modulated by electronic stimuli (Hang et al. 1995, Skorjanc et al. 1998, Brutsaert et al. 2002, Tang et al. 2004). Additionally, Asmussen and Soukup (1991) suggest that reflex-mediated motoneuronal activity decreases due to a attenuated muscle spindle feedback during $\mathrm{HU}$, which may affect the expression of VEGF. Therefore, it is likely that alteration in EMG activity during HU may be associated with VEGF expression. In this regard, the response of VEGF expression to $\mathrm{HU}$ is obviously different from that to muscle denervation.

In the current study, we observed the expression of VEGF receptors (Flt-1, KDR/Flk-1, and neuropilin-1) were down-regulated, while that of VEGF remained unchanged in hindlimb unweighted muscle. From the result of the gene expression analysis, our data suggest that VEGF/KDR/Flk-1/neuropilin-1 signaling may be attenuated, resulting in capillary regression after HU. This possibility may be supported by the observation by Tang et al. (2004) who reported that capillary regression was observed in VEGF-inactivated regions of skeletal muscle from VEGFloxP transgenic mice in which all three VEGF isoforms were inactivated. They demonstrated that capillary regression was accompanied by the appearance of TUNEL-positive apoptotic endothelial cells. Therefore, insufficient VEGFdependent signal may initiate the apoptotic pathway in endothelial cells and lead to capillary regression.

Although the role of Flt-1 in the adult animals is less clearly defined compared to that of KDR/Flk-1, Flt-1 mRNA is expressed in both proliferating and quiescent endothelial cells, suggesting a role for this receptor in the maintenance of endothelial cells (Peters et al. 1993). We observed that Flt-1 protein was expressed in endothelial cells of normal and regenerating skeletal muscle (Wagatsuma et al. 2006). Therefore, we hypothesize that Flt-1 may contribute to endothelial cell integrity during HU.

We observed that the expression of angiopoietin-1, angiopoietin-2, and Tie-2 were down-regulated in hindlimb unweighted animals, suggesting that angiopoietin-1/Tie-2 signaling may be attenuated despite down-regulation of angiopoietin-2. Consequently, we calculated the ratio of angiopoietin-2-to-angiopoietin-1 to compare ambulatory control with $\mathrm{HU}$, because changes in the ratio are thought to determine whether the net effect of the angiopoietins is to stabilize or destabilize the vasculature. Indeed, the ratio of angiopoietin-2-toangiopoietin-1 is found to increase with angiogenesis 
induced by exercise training (Lloyd et al. 2003) and cutaneous wound hearing (Kampfer et al. 2001), due to larger increase in angiopoietin-2 than in angiopoieti-1. Interestingly, we also observed the ratio increased after $\mathrm{HU}$, due to larger decrease in angiopoieti-1 than in angiopoietin-2. This observation is consistent with our previous study using muscle denervation model (Wagatsuma and Osawa 2006). Although further studies are needed to elucidate the role of angiopoietin-2 in capillary regression induced by $\mathrm{HU}$, our data suggest that angiopoietin-1/Tie-2 signaling may be attenuated.

In conclusion, we demonstrated that the expression of VEGF receptors, Flt-1, KDR/Flk-1, neuropilin-1, angiopoietin-1, -2 , and angiopoietin receptor, Tie-2 were down-regulated in the atrophied muscle where capillary regression occur after $\mathrm{HU}$, suggesting that attenuation of angiopoietin-1/Tie-2 signaling concomitant with decreased VEGF/KDR/Flk-1/ neuropilin-1 signaling may result in capillary regression induced by HU. Although the mechanism(s) of reduction of motor activity and lack of load bearing by $\mathrm{HU}$ regulates the expression of angiogenic factors remain to be identified, our data may explain, at least in part, capillary regression in the atrophied muscle induced by HU.

\section{Conflict of Interest}

There is no conflict of interest.

\section{Acknowledgements}

This work was partly supported by the Grant-in-Aid for Scientific Research from Japan Society for the Promotion of Science (grant no. 19700524 to A.W.) and Japan Science Society and by the Sasakawa Scientific Research Grant from the Japan Science Society (to A.W.).

\section{References}

ALFORD EK, ROY RR, HODGSON JA, EDGERTON VR: Electromyography of rat soleus, medial gastrocnemius, and tibialis anterior during hind limb suspension. Exp Neurol 96: 635-649, 1987.

ASAHARA T, CHEN D, TAKAHASHI T, FUJIKAWA K, KEARNEY M, MAGNER M, YANCOPOULOS GD, ISNER JM: Tie2 receptor ligands, angiopoietin-1 and angiopoietin-2, modulate VEGF-induced postnatal neovascularization. Circ Res 83: 233-240, 1998.

ASMUSSEN G, SOUKUP T: Arrest of developmental conversion of type II to type I fibres after suspension hypokinesia. Histochem J 23: 312-322, 1991.

BEY L, AKUNURI N, ZHAO P, HOFFMAN EP, HAMILTON DG, HAMILTON MT: Patterns of global gene expression in rat skeletal muscle during unloading and low-intensity ambulatory activity. Physiol Genomics 13: 157-167, 2003.

BRUTSAERT TD, GAVIN TP, FU Z, BREEN EC, TANG K, MATHIEU-COSTELLO O, WAGNER PD: Regional differences in expression of VEGF mRNA in rat gastrocnemius following $1 \mathrm{hr}$ exercise or electrical stimulation. BMC Physiol 2: 8, 2002.

CROSS MJ, DIXELIUS J, MATSUMOTO T, CLAESSONI-WELSH L: VEGF-receptor signal transduction. Trends Biochem Sci 28: 488-494, 2003.

DAPP C, SCHMUTZ S, HOPPELER H, FLUCK M: Transcriptional reprogramming and ultrastructure during atrophy and recovery of mouse soleus muscle. Physiol Genomics 20: 97-107, 2004.

DESPLANCHES D, MAYET MH, SEMPORE B, FLANDROIS R: Structural and functional responses to prolonged hindlimb suspension in rat muscle. $J$ Appl Physiol 63: 558-563, 1987.

DESPLANCHES D, KAYAR SR, SEMPORE B, FLANDROIS R, HOPPELER H: Rat soleus muscle ultrastructure after hindlimb suspension. J Appl Physiol 69: 504-508, 1990.

DESPLANCHES D, FAVIER R, SEMPORE B, HOPPELER H: Whole body and muscle respiratory capacity with dobutamine and hindlimb suspension. $J$ Appl Physiol 71: 2419-2424, 1991.

FAM NP, VERMA S, KUTRYK M, STEWART DJ: Clinician guide to angiogenesis. Circulation 108: 2613-2618, 2003.

FERRARA N: Molecular and biological properties of vascular endothelial growth factor. $J$ Mol Med 77: 527-543, 1999.

FERRARA N: Role of vascular endothelial growth factor in regulation of physiological angiogenesis. Am J Physiol 280: C1358-C1366, 2001. 
FERRARA N, GERBER HP, LECOUTER J: The biology of VEGF and its receptors. Nat Med 9: 669-676, 2003.

FUJINO H, KOHZUKI H, TAKEDA I, KIYOOKA T, MIYASAKA T, MOHRI S, SHIMIZU J, KAJIYA F: Regression of capillary network in atrophied soleus muscle induced by hindlimb unweighting. J Appl Physiol 98: 1407-1413, 2005.

GERBER HP, CONDORELLI F, PARK J, FERRARA, N: Differential transcriptional regulation of the two vascular endothelial growth factor receptor genes. Flt-1, but not Flk-1/KDR, is up-regulated by hypoxia. $J$ Biol Chem 272: 23659-23667, 1997.

GERBER HP, MCMURTREY A, KOWALSKI J, YAN M, KEYT BA, DIXIT V, FERRARA, N:. Vascular endothelial growth factor regulates endothelial cell survival through the phosphatidylinositol 3'-kinase/Akt signal transduction pathway. Requirement for Flk-1/KDR activation. J Biol Chem 273: 30336-30343, 1998.

HAGA M, CHEN A, GORTLER D, DARDIK A, SUMPIO BE: Shear stress and cyclic strain may suppress apoptosis in endothelial cells by different pathways. Endothelium 10: 149-157, 2003.

HANG J, KONG L, GU JW, ADAIR TH: VEGF gene expression is upregulated in electrically stimulated rat skeletal muscle. Am J Physiol 269: H1827-H1831, 1995.

IYER NV, KOTCH LE, AGANI F, LEUNG SW, LAUGHNER E, WENGER RH, GASSMANN M, GEARHART JD, LAWLER AM, YU AY, SEMENZA GL: Cellular and developmental control of $\mathrm{O}_{2}$ homeostasis by hypoxiainducible factor 1 alpha. Genes Dev 12: 149-162, 1998.

JIANG BH, ZHENG JZ, LEUNG SW, ROE R, SEMENZA GL: Transactivation and inhibitory domains of hypoxiainducible factor 1alpha. Modulation of transcriptional activity by oxygen tension. J Biol Chem 272: 19253$19260,1997$.

KAMPFER H, PFEILSCHIFTER J, FRANK S: Expressional regulation of angiopoietin-1 and -2 and the tie-1 and -2 receptor tyrosine kinases during cutaneous wound healing: a comparative study of normal and impaired repair. Lab Invest 81: 361-373, 2001.

KANO Y, SHIMEGI S, TAKAHASHI H, MASUDA K, KATSUTA S: Changes in capillary luminal diameter in rat soleus muscle after hind-limb suspension. Acta Physiol Scand 169: 271-276, 2000.

LEVY AP, LEVY NS, WEGNER S, GOLDBERG MA: Transcriptional regulation of the rat vascular endothelial growth factor gene by hypoxia. J Biol Chem 270: 13333-13340, 1995.

LLOYD PG, PRIOR BM, YANG HT, TERJUNG RL: Angiogenic growth factor expression in rat skeletal muscle in response to exercise training. Am J Physiol 284: H1668-H1678, 2003.

MAGNUSSON C, SVENSSON A, CHRISTERSON U, TAGERUD S: Denervation-induced alterations in gene expression in mouse skeletal muscle. Eur J Neurosci 21: 577-580, 2005.

MAXWELL PH, WIESENER MS, CHANG GW, CLIFFORD SC, VAUX EC, COCKMAN ME, WYKOFF CC, PUGH CW, MAHER ER, RATCLIFFE PJ: The tumour suppressor protein VHL targets hypoxia-inducible factors for oxygen-dependent proteolysis. Nature 399: 271-275, 1999.

MCCARTHY JJ, FOX AM, TSIKA GL, GAO L, TSIKA RW: beta-MHC transgene expression in suspended and mechanically overloaded/suspended soleus muscle of transgenic mice. Am J Physiol 272: R1552-R1561, 1997.

MCDONALD KS, DELP MD, FITTS RH: Effect of hindlimb unweighting on tissue blood flow in the rat. $J$ Appl Physiol 72: 2210-2218, 1992.

MOREY-HOLTON E, WRONSKI TJ: Animal models for simulating weightlessness. Physiologist 24: S45-S48, 1981.

MOREY-HOLTON ER, GLOBUS RK: Hindlimb unloading rodent model: technical aspects. J Appl Physiol 92: 1367$1377,2002$.

OVERTON JM, WOODMAN CR, TIPTON CM: Effect of hindlimb suspension on $\mathrm{VO}_{2}$ max and regional blood flow responses to exercise. J Appl Physiol 66: 653-659, 1989.

PETERS KG, DE VRIES C, WILLIAMS LT: Vascular endothelial growth factor receptor expression during embryogenesis and tissue repair suggests a role in endothelial differentiation and blood vessel growth. Proc Natl Acad SciUSA 90: 8915-8919, 1993.

SALCEDA S, CARO J: Hypoxia-inducible factor 1alpha (HIF-1alpha) protein is rapidly degraded by the ubiquitinproteasome system under normoxic conditions. Its stabilization by hypoxia depends on redox-induced changes. J Biol Chem 272: 22642-22647, 1997. 
SCHNURCH H, RISAU W: Expression of tie-2, a member of a novel family of receptor tyrosine kinases, in the endothelial cell lineage. Development 119: 957-968, 1993.

SEMENZA GL: Regulation of mammalian $\mathrm{O}_{2}$ homeostasis by hypoxia-inducible factor 1. Annu Rev Cell Dev Biol 15: 551-578, 1999.

SEMENZA GL: HIF-1: mediator of physiological and pathophysiological responses to hypoxia. J Appl Physiol 88: 1474-1480, 2000.

SHIH SC, ROBINSON GS, PERRUZZI CA, CALVO A, DESAI K, GREEN JE, ALI IU, SMITH LE, SENGER DR: Molecular profiling of angiogenesis markers. Am J Pathol 161: 35-41, 2002.

SIMPSON DA, FEENEY S, BOYLE C, STITT AW: Retinal VEGF mRNA measured by SYBR green I fluorescence: A versatile approach to quantitative PCR. Mol Vis 6: 178-183, 2000.

SKORJANC D, JASCHINSKI F, HEINE G, PETTE D: Sequential increases in capillarization and mitochondrial enzymes in low-frequency-stimulated rabbit muscle. Am J Physiol 274: C810-C818, 1998.

SOKER S, TAKASHIMA S, MIAO HQ, NEUFELD G, KLAGSBRUN M: Neuropilin-1 is expressed by endothelial and tumor cells as an isoform-specific receptor for vascular endothelial growth factor. Cell 92: 735-745, 1998.

STROKA DM, BURKHARDT T, DESBAILLETS I, WENGER RH, NEIL DA, BAUER C, GASSMANN M, CANDIANS D: HIF-1 is expressed in normoxic tissue and displays an organ-specific regulation under systemic hypoxia. FASEB $J$ 15: 2445-2453, 2001.

TALMADGE RJ: Myosin heavy chain isoform expression following reduced neuromuscular activity: potential regulatory mechanisms. Muscle Nerve 23: 661-679, 2000.

TANG K, BREEN EC, WAGNER H, BRUTSAERT TD, GASSMANN M, WAGNER PD: HIF and VEGF relationships in response to hypoxia and sciatic nerve stimulation in rat gastrocnemius. Respir Physiol Neurobiol 144: 71-80, 2004.

TANG K, BREEN EC, GERBER HP, FERRARA NM, WAGNER PD: Capillary regression in vascular endothelial growth factor-deficient skeletal muscle. Physiol Genomics 18: 63-69, 2004.

THIJSSEN VL, BRANDWIJK RJ, DINGS RP, GRIFFIOEN AW: Angiogenesis gene expression profiling in xenograft models to study cellular interactions. Exp Cell Res 299: 286-293, 2004.

WAGATSUMA A: Effect of aging on expression of angiogenesis-related factors in mouse skeletal muscle. Exp Gerontol 41: 49-54, 2006.

WAGATSUMA A, OSAWA T: Time course of changes in angiogenesis-related factors in denervated muscle. Acta Physiol 187: 503-509, 2006.

WAGATSUMA A, TAMAKI H, OGITA F: Capillary supply and gene expression of angiogenesis-related factors in murine skeletal muscle following denervation. Exp Physiol 90: 403-409, 2005.

WAGATSUMA A, TAMAKI H, OGITA F: Sequential expression of vascular endothelial growth factor, Flt-1, and KDR/Flk-1 in regenerating mouse skeletal muscle. Physiol Res 55: 633-640, 2006.

WOODMAN CR, SCHRAGE WG, RUSH JW, RAY CA, PRICE EM, HASSER EM, LAUGHLIN MH: Hindlimb unweighting decreases endothelium-dependent dilation and eNOS expression in soleus not gastrocnemius. J Appl Physiol 91: 1091-1098. 2001.

YAO R, COOPER, GM: Requirement for phosphatidylinositol-3 kinase in the prevention of apoptosis by nerve growth factor. Science 267: 2003-2006, 1995.

ZIADA AM, HUDLICKA O, TYLER KR, WRIGHT AJ: The effect of long-term vasodilatation on capillary growth and performance in rabbit heart and skeletal muscle. Cardiovasc Res 18: 724-732, 1984. 